\title{
Blueshifted dielectric properties and optical conductivity of new nanoscale nickel-(II)-tetraphenyl-21H,23H-porphyrin films as a function of UV illumination for energy storage applications
}

\author{
A. El-Denglawey ${ }^{1,2} \cdot$ H. A. Alburaih ${ }^{3} \cdot$ M. M. Mostafa ${ }^{4,5} \cdot$ M. S. S. Adam ${ }^{6,7}$. \\ M. M. Makhlouf ${ }^{4,8}$
}

Received: 16 July 2020 / Accepted: 22 May 2021 / Published online: 24 June 2021

(c) The Author(s), under exclusive licence to Springer Science+Business Media, LLC, part of Springer Nature 2021

\begin{abstract}
Pristine thermally evaporated nickel-(II)-tetraphenyl-21H,23H-porphyrin (NiTPP) thin films are amorphous, but after 4 and $8 \mathrm{~h}$ of UV illumination, the films become crystalline with preferred orientations of (112), (103) and (004) and crystallite sizes of (13, 18, 16) and $(42,31,38) \mathrm{nm}$ after 4 and $8 \mathrm{~h}$, respectively. After UV illumination for 4 and $8 \mathrm{~h}$, the NiTPP thin films are characterized by blueshifted absorption coefficients, increasing the optical and fundamental gap values and decreasing the dispersion parameter values. The dielectric properties display energy storage regions corresponding to the peak values of optical conductivity, which provides an elegant confirmation of the tailoring and tuning of band gaps, energy storage properties and optical conductivity by UV illumination time. Therefore, NiTPP films may be good candidates for environmental and energy storage applications.
\end{abstract}

Keywords Phase and optical properties $\cdot$ Energy conversion and storage $\cdot$ Photovoltaic system $\cdot$ Optical conductivity $\cdot$ Nanomaterials $\cdot$ Thin films

A. El-Denglawey

a.denglawey@tu.edu.sa; denglawey@yahoo.com

1 Physics Department, Turabah University College, Taif University, Turabah 21995, Saudi Arabia

2 Nano \& Thin Film Laboratory, Physics Department, Faculty of Science, South Valley University, Qena 83523, Egypt

3 Physics Department, Faculty of Science, Princess Nourah Bint Abdulrahman University, Riyadh, Kingdom of Saudi Arabia

4 Science \& Technology Department, Rania University College, Taif University, Rania 12975, Kingdom of Saudi Arabia

5 Physics Department, Faculty of Science, Suez University, Suez, Egypt

6 Chemistry Department, Faculty of Science, King Faisal University, 380, Al Hassa-31982,

Al Hofuf, Kingdom of Saudi Arabia

7 Chemistry Department, Faculty of Science, Sohag University, Sohag-82534, Egypt

8 Department of Physics, Damietta Cancer Institute, Damietta, Egypt 


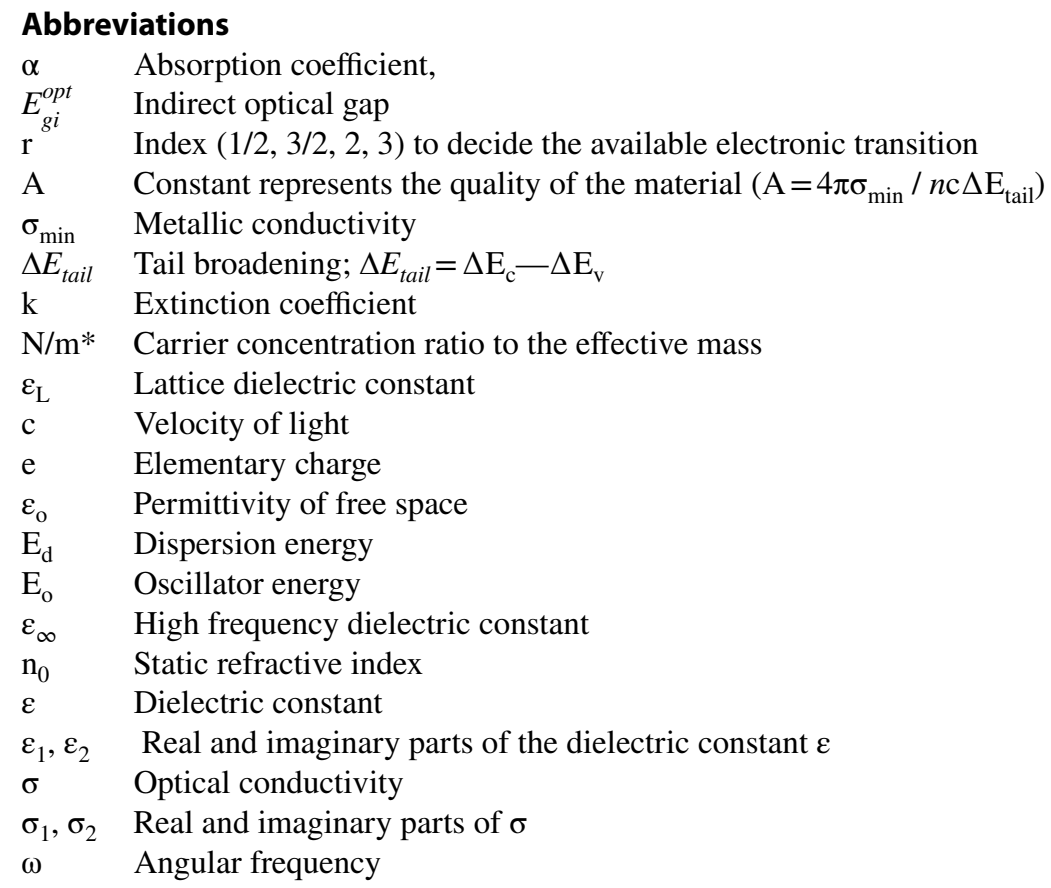

\section{Introduction}

Different types of energy are the basic constituents of human activities. Therefore, the demand for energy will increase (Fella et al. 2020; Alptekin et al. 2020) due to the increase in population; agriculture; medicine; industry; transportation; scientific research; health; military and civil aspects; communications; electronics and new issues, such as the COVID-19 crisis. (Hassan and Al-Ta'ii 2020). Therefore, decreasing energy consumption is no longer optional but compulsory, and energy should be saved to satisfy the abovementioned purposes (Alptekin et al. 2020; El-Denglawey et al. 2020; Zhang et al. 2016). Energy conservation, savings and storage (ECSS) as a clean energy method can be used to avoid adverse influences on the environment and to counter energy shortages (Alptekin et al. 2020; El-Denglawey et al. 2020; Zhang et al. 2016).

Easily excited electrons and highly dielectric materials can be used to increase the ECSS, in which conductivity depends on the dielectric constant, capacitance and consequently on the area of panels that are used in the manufacture of capacitors for energy storage applications (Zhang et al. 2016; Vidya and Thomas 2018).

NiTPP, as an organic semiconductor, has many advantages for use in ECSS applications. NiTPP shows stable thermal and chemical properties, and it can be thermally evaporated to form high quality thin films (Anderson 1999) that are stretchable, highly flexible, rollable (Savagatrup et al. 2014), and deformable. Additionally, NiTPP is a high softness material with $\pi$-conjugation (Chortos et al. 2014). NiTPP is lightweight and has a high absorption coefficient in the visible range, allowing for inexpensive photovoltaic (PV) panels (Pfeiffer et al. 2003; Tang 1986). NiTPP can be synthetically tuned (Lukyanov and Andrienko 2010). Furthermore, NiTPP can undergo low temperature deposition techniques 
independent of substrate defects, and can be easily deposited on different substrates; moreover, it is easily modified, able to be mass produced (Jason 2012) and harmless to the environment (Chen et al. 2019).

NiTPP as an organic semiconductor thin film has a wide range of applications: ECSS, PV devices, flexible PV panels (Root et al. 2017), photodetectors, light-emitting devices, photocopiers, stretchable batteries (Kaltenbrunner et al. 2010), laser printers (Pfeiffer et al. 2003), robust portable devices, organic transistors, storage media (Jason 2012), and highpower electrochemical energy-storage systems; furthermore, it can undergo light energy conversion, and may be used as potential electrodes in batteries (Gao et al. 2017; Karger et al. 2019).

The characterization and properties of organic or inorganic materials may be affected by different operators (El-Denglawey et al. 2018), such as physical and/or artificial aging for a short or long time (Saiter 2001; El-Denglawey et al.; 2016; El-Denglawey et al; 2015; Alburaih and El-Denglawey 2017), annealing (Özdal et al. 2020; Al-Harbi et al. 2020), illumination (Li et al. 2020), deposition method (Al-Asbahi et al. 2020), preparation factors (Alburaih and El-Denglawey 2017), chemical ratios (Figa et al. 2015), doping (Kulyk et al. 2020; Leo and Hummert 2013), chemical purity (Andirova et al. 2016), material form (thin or bulk) (Deepthi et al. 2020), thickness (Idris et al. 2020), structural phases and parameters (Souleh et al. 2020; Kumar et al. 2020), alloying (Yang et al. 2020), film holder type or substrate (Wang et al. 2020), application of electric fields (Smokal 2020), and radiation (Tamilselvana et al. 2014).

Radiation has thermal and PV applications and is divided into natural and artificial sources (Kambezidis 2012). The solar spectrum, as natural radiation, contains ionizing or high-energy radiation, such as ultraviolet (UV) radiation, and nonionizing or low-energy radiation, such as infrared (IR, also called thermal radiation), visible light (Vis.), microwave and radio waves (Kambezidis 2012; Saad et al. 2019).

The solar spectrum consists of UV (6\%), Vis. (52\%) and IR (42\%) inside the atmosphere and 8\%, 39\% and 53\% outside the atmosphere (Moan 2001). UV, as a partial component of the solar spectrum, is considered ionized or high-energy radiation, so it may affect the structural, optical and storage energy properties of NiTPP films.

The blueshift, dielectric properties and optical conductivity of NiTPP films as a function of UV illumination time for energy storage applications have not been reported thus far according to available data. Therefore, the above properties are the aims of this article.

\section{Experimental}

NiTPP films $(300 \mathrm{~nm})$ were prepared by a thermal evaporation technique from powder NiTPP (6 N purity) provided by Sigma-Aldrich Company on a glass substrate for X-ray diffraction (XRD) and on a quartz substrate for optical property measurements using an Edwards coating unit (E306A, UK).

To illuminate the NiTPP films for 4 and $8 \mathrm{~h}$, the detector was placed at a distance of $2.0 \mathrm{~cm}$ from the UV source. The UV illumination process was carried out by utilizing a UV lamp with a power of $8.0 \mathrm{~W}$.

A Philips-1710 X-ray diffractometer with the following qualifications was used to study the structural properties: $\mathrm{CuK} \alpha$ radiation source $(\lambda=1.5406), 300 \mathrm{~K}, 40 \mathrm{kV}, 30 \mathrm{~mA}$ and a scanning speed of $3.761 \mathrm{~min}^{-1}$. 
The crystallite size (D) was determined by the Scherrer equation (Warren 1953; Williamson and Hall 1953; El-Nahass et al. 2016; El-Denglawey et al. 2018a; Soliman et al 2015):

$$
D=\frac{L \lambda}{\beta \cos \theta}
$$

where $\mathrm{L}$ and $\beta$ represent the constant of unity value and the full width at half maximum (FWHM) of the peak in radians, respectively.

A computerized Shimadzu UV-2100 double-beam UV-VIS scanning spectrophotometer was used to measure the transmittance $(\mathrm{T})$ and reflectance $(\mathrm{R})$ for the as-prepared and UVilluminated NiTPP films at a normal incidence within a wavelength range (200-1100 nm) for optical property characterization.

Further details can be found at El-Denglawey 2018 (Dongol et al. 2004, 2016).

The following chart contains 10 (2-11) equations that describe and summarize the procedure of how optical properties and optical constants can be calculated depending on the $\mathrm{T}$ and $\mathrm{R}$ data in this scenario and the details are described in (Tauc 1976; El-Denglawey 2018a; El-Denglawey et al. 2016, Wemple and DiDomenico 1970; Tanaka 1980; Dongol et al. 2004).

\section{Results and discussion}

\subsection{Structural properties}

The structure of NiTPP has been reported by many researchers (Smith 1975; Gamboa et al. 2010; Dongol et al. 2012; Al-Muntaser et al. 2018; ), as shown in Fig. 1a. XRD of a pristine NiTPP film shows an amorphous structure, as shown in Fig. 1b. No sharp peaks can be identified, and only a hump within $2 \theta\left(13.8-37.4^{\circ}\right)$ is observed, which characterizes the amorphous phase (Warren 1953; Williamson and Hall 1953; El-Denglawey et al. 2020; El-Nahass et al. 2016; El-Denglawey 2018; Soliman et al. 2015). The structure of the NiTPP films is developed, and the crystalline structure is pronounced after 4 and $8 \mathrm{~h}$ of UV illumination.

Three XRD peaks are revealed at $2 \theta=15.19^{\circ}, 20.13^{\circ}$, and $25.43^{\circ}$ corresponding to preferred orientations of (112), (103) and (004), respectively (see Fig. 1c,d). Proceeding with the experimental techniques (Warren 1953; Williamson and Hall 1953; El-Nahass et al. 2016; El-Denglawey 2018a; Soliman et al. 2015), the calculated crystallite sizes at 4 and $8 \mathrm{~h}$ of UV-illumination provide NiTPP films that are $(13,18,16)$ and $(42,31,38) \mathrm{nm}$, respectively. One can observe that the $2 \theta$ range of the three identified peaks is already included within the $2 \theta$ range of the hump representing the amorphous state (13.8-37.4 ${ }^{\circ}$ ).

This observation provides more structural details (Warren 1953; Williamson and Hall 1953; El-Denglawey 2018). The amorphous hump contains three primary overlapping peaks, which can be identified with further UV illumination time.

In detail, a material is called amorphous if it is prepared by melt quenching or supercooling as a bulk or thin film on a substrate. Therefore, the produced material is stressed and contains many defects.

There is not enough time for atoms to satisfy and order their bonds. NiTPP films are deposited at room temperature, and consequently, chemical bonds can not satisfy their required electrons, so dangling bonds and localized states are introduced. Dangling 


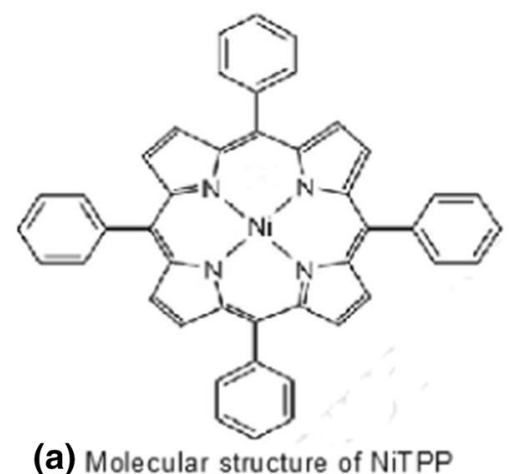

(a) Molecular structure of NiTPP

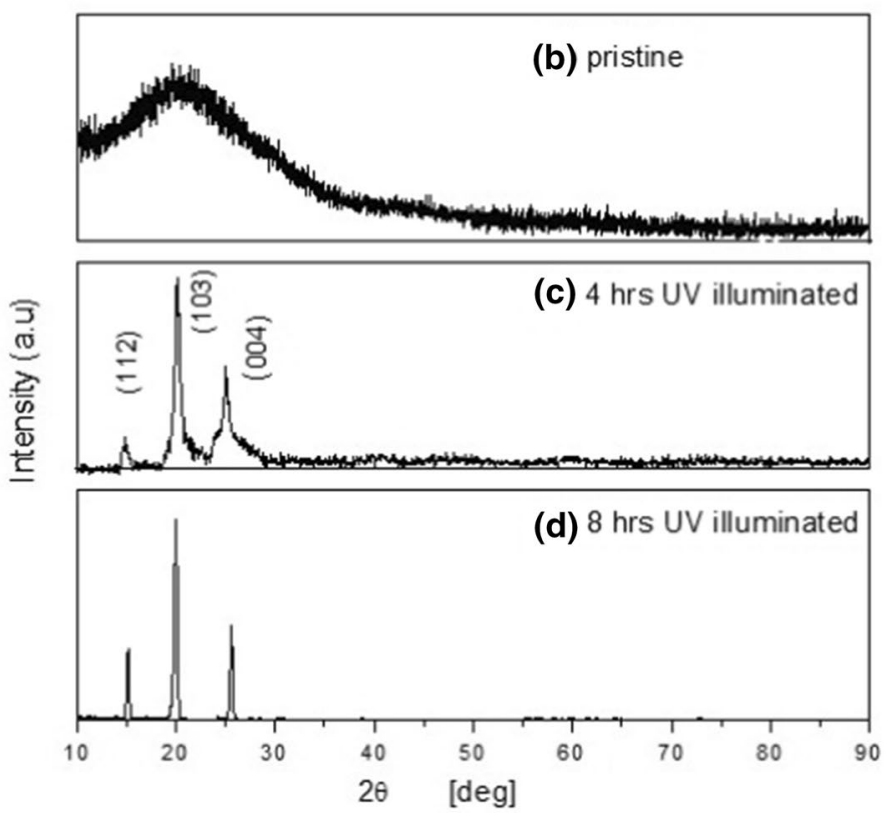

Fig. 1 Molecular structure and XRD of NiTPP films

bonds and localized states, which are known as defects, create band tails through the band gap (Tauc 1976; Trugler 2016; El-Denglawey 2018a). Therefore, it is normal to expect pristine NiTPP films to be amorphous, and the result of this issue causes a hump in Fig. 1b. UV illumination of the NiTPP films for 4 and $8 \mathrm{~h}$ provides sufficient energy to these dangling bonds or defects to satisfy their bonds; consequently, more ordered and preferred orientations, namely, (112), (103) and (004), appear with the above mentioned calculated crystallite sizes, as shown in Fig. 1c,d.

The increase in $\mathrm{D}$ values provides an elegant confirmation of the structural improvement, which coincides with the findings of (Makhlouf and El-Denglawey 20181-Denglawey 2018). 


\subsection{Optical properties}

\subsubsection{T and R characterization}

According to the proceeding experimental sequence, $\mathrm{T}$ and $\mathrm{R}$ are measured and illustrated in Fig. 2. The values of $\mathrm{T}$ are enlarged, and its values at $\lambda=1100 \mathrm{~nm}$ are 85,88 and 92 for pristine, 4 and $8 \mathrm{~h}$ of UV illumination, respectively, while $\mathrm{R}$ is the opposite. T displays a wavy shape within the absorption region $(\lambda=400-750 \mathrm{~nm})$, and a blueshift is observed (El-Denglawey et al. 2010).

The absorption process occurs through this region, and direct or indirect electronic transitions may be available (Tauc 1976; El-Denglawey 2018; Mott and Davis 1971; Pankove 1971). No significant changes can be observed within the transparent or nonabsorbing region at $\lambda>750 \mathrm{~nm}$ (El-Denglawey et al. 2020; Wemple and DiDomenico 1969; Mott and Davis 1971; Pankove 1971).

\subsubsection{Absorption coefficient, skin depth and optical gap calculation}

Briefly, $\alpha$ can be estimated using Eqs. $2-4$ in the flow chart. The obtained values of $\alpha$ show that both pristine and UV-illuminated NiTPP films are high absorption materials, $\alpha>10^{4} \mathrm{~cm}^{-1}$ (Tauc 1976; Mott and Davis 1971; Pankove 1971; El-Nahass et al. 2012).

It was reported that (Barmak and Coffey 2014) the skin depth $(\gamma)$ corresponds to the penetration distance of the electric field of the incident light through the pristine and UVilluminated NiTPP films.

Herein, $\gamma$ is identified as the inverse of $\alpha, \gamma=(1 / \alpha)$ (see the flow chart). At low energy or at a high wavelength and low frequency, the skin depth becomes large due to the transparency of the film and the absence of the absorption process (Gilberdt 1982). More knowledge about $\gamma$ is available at (Qiang et al. 2018).

Figure $3 \mathrm{a}, \mathrm{b}$ shows the relation between $\gamma$ and $\lambda$. At low values of $\lambda$, $\mathrm{h} \nu$ corresponds to its topmost values. The NiTPP films absorb the $\mathrm{h} \nu$ of the incident UV illumination and consequently inhibit an increase in $\gamma$. As $\lambda$ increases, the $h \nu$ values become low and $\alpha$ decreases. Accordingly, $\gamma$ increases and tends to its topmost values, while the values of $\alpha$ decrease and disappear due to the transparency of the NiTPP films in the nonabsorbing region.

Fig. $2 \mathrm{~T}$ and $\mathrm{R}$ of NiTPP films

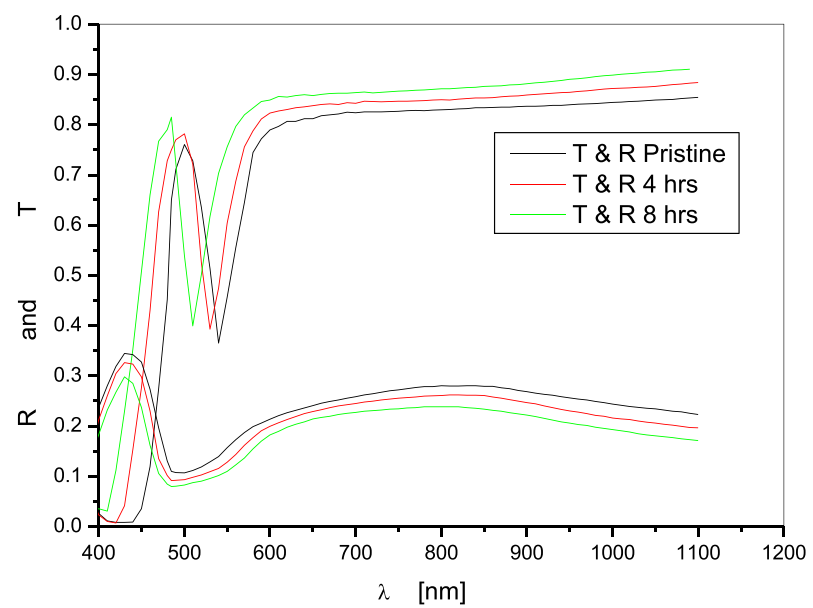


Fig. 3 Skin depth and absorbance of NiTPP films
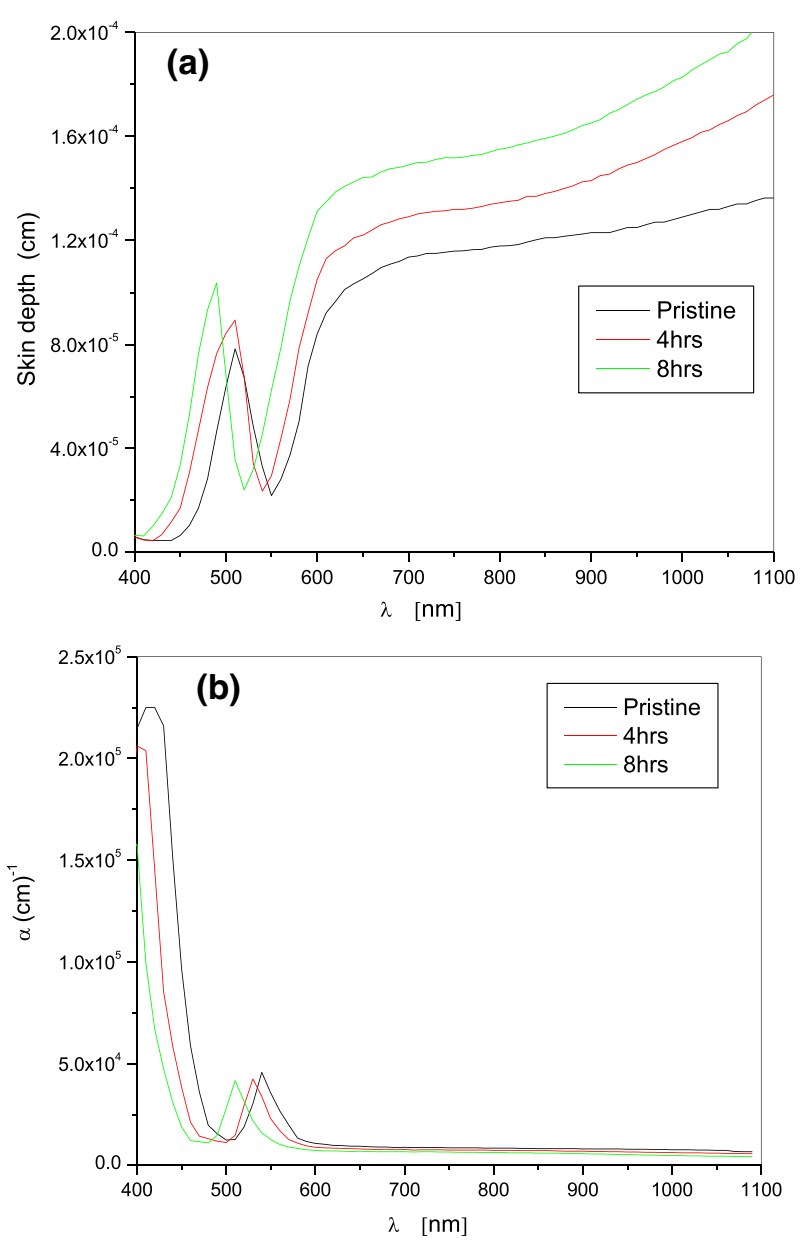

Two energy gaps are observed (Tauc 1976; Mott and Davis 1971; Pankove 1971; ElDenglawey et al. 2015): an optical gap $\left(E_{g}^{\text {opt }}\right)$ of approximately $2 \mathrm{eV}$ and a fundamental gap $\left(\mathrm{E}_{\mathrm{g})}\right.$ of approximately $2.5 \mathrm{eV}$.

An indirect electronic transition is observed according to the calculated value of " $\mathrm{r}$ " $(\mathrm{r}=2)$. Accordingly, the indirect optical gap $\left(E_{g i}^{o p t}\right)$ and the constant A are calculated using eqs. 5 and 6 (see Fig. 4).

The electronic transition types and other details are available at (Tauc 1976; Mott and Davis 1971; Pankove 1971; El-Denglawey 2018; Figà et al. 2009).

Tabulated values of $E_{g i}^{o p t}, \mathrm{E}_{\mathrm{g}}$ and the constant A reveal a blueshift in the absorption edge because of the 4 and $8 \mathrm{~h}$ of UV illumination, as shown in Table 1 (El-Denglawey et al. 2010). Combining the structural details with the optical characterizations provides specific explanations of the increased values of $E_{g i}^{o p t}, \mathrm{E}_{\mathrm{g}}$ and the constant $\mathrm{A}$. The blueshift of $\mathrm{T}$ means that the T-curves have shifted to shorter wavelengths (high energy), which causes increasing values of $E_{g i}^{o p t}$. When the pristine NiTPP films are exposed to UV illumination for 4 and $8 \mathrm{~h}$, the films absorb the UV illumination energy. The dangling bonds or localized states that cause the amorphous structure hump in Fig. 1b exploit the absorbed energy 
Fig. $4(\alpha h \nu)^{1 / 2}$ Vs $(h \nu)$ of NiTPP films

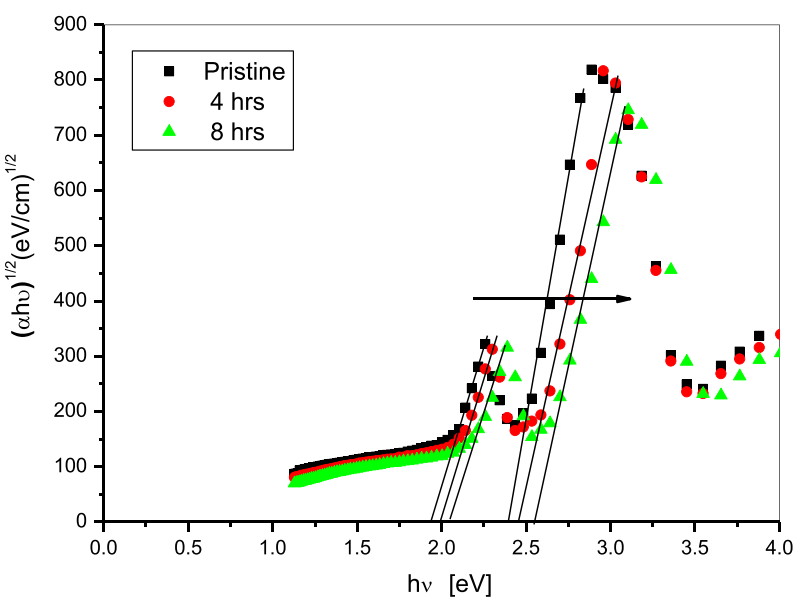

to reorder themselves. Therefore, the band tails of the defects decrease, more structural improvement is produced, and the crystalline phase appears as new peaks in Fig. 1c,d. The decrease in band tails is accompanied by an increase in the absorption edge, absorption process and indirect electronic transmission.

The increase in the absorption edge is known as a blueshift. As a result of this issue, $E_{g i}^{o p t}, \mathrm{E}_{\mathrm{g}}$ and the constant A values are increased (Mott and Davis 1971; Pankove 1971; Tauc 1976; El-Denglawey 2018a). According to (Wang et al. 2019), the increases in the $E_{g i}^{o p t}, \mathrm{E}_{\mathrm{g}}$ and constant $\mathrm{A}$ values leads to an improvement in the energy storage properties of NiTPP. The obtained data agrees with (Hassan and Al-Ta'ii 2020; Makhlouf and ElDenglawey 20181-Denglawey 2018).

\subsubsection{Refractive index and dielectric properties}

The determination of (n) values was processed according to Eq. 7 (Wemple and DiDomenico 1970; El-Denglawey 2013) and is shown in Fig. 5. The $\mathrm{n}$ value shows both anomalous and normal dispersion at $\lambda \leq 750 \mathrm{~nm}$ and $\lambda>750 \mathrm{~nm}$, respectively, and the $\mathrm{k}$ values tend to zero at $\lambda>750$.

Furthermore, N/m* can be estimated according to Eq. 8 from the slope of the $n^{2}$ vs. $\lambda^{2}$ relation, while $\varepsilon_{\mathrm{L}}=\left(\mathrm{n}^{2}\right)$ can be estimated from the intercept, as illustrated in Fig. 6 .

$\mathrm{E}_{\mathrm{o}}, \mathrm{E}_{\mathrm{d}}$ and $\varepsilon_{\infty}$ can be determined according to Eq. 9 from the slope and the intercept of $\left(n^{2}(h v)-1\right)^{-1}$ vs. $(\mathrm{h} v)^{2}$ (Wemple and DiDomenico 1969; El-Denglawey 2020), as shown in Fig. 7.

Table 1 shows the obtained increased values of $N / \mathrm{m}^{*}$ and the decreased values of $\varepsilon_{\mathrm{L}}, \mathrm{n}$, $\mathrm{E}_{\mathrm{o}}, \mathrm{E}_{\mathrm{d}}, \varepsilon_{\infty}$ and $\mathrm{n}_{0}\left(\varepsilon_{\infty}=\mathrm{n}_{0}^{2}\right)$, which coincide with (Alburaih and El-Denglawey 2017).

The dielectric constant $(\varepsilon)$ and its two parts, real $\left(\varepsilon_{1)}\right.$ and imaginary $\left(\varepsilon_{2}\right)$, are correlated to $\mathrm{n}$ and $\mathrm{k}$, as shown in Eq. 10 (Wemple and DiDomenico 1969; El-Denglawey 2020). Figure $8 \mathrm{a}$,b displays the $\varepsilon_{1}, \varepsilon_{2}$ and loss tangent $(\tan (\delta)$ vs. $(\mathrm{h} v))$ as a function of 4 and $8 \mathrm{~h} \mathrm{UV}$ illumination. The curves of $\varepsilon_{1}$ and $\varepsilon_{2}$ decrease as the UV illumination time increases. There is a feature difference between $\varepsilon_{1}$ and $\varepsilon_{2}$ due to the effect of $\mathrm{k}$. The $\varepsilon_{1}$ values are higher than $\varepsilon_{2}$, which finally indicates that $\varepsilon_{2}$ is seriously affected by $\mathrm{k}$; in contrast, $\varepsilon_{1}$ shows the opposite behavior (Moss 1973). $\varepsilon_{1}$ and $\varepsilon_{2}$ display a maximum peak edge that starts at approximately $2.5 \mathrm{eV}$ and shifts to higher energy values with an increasing UV illumination time. 


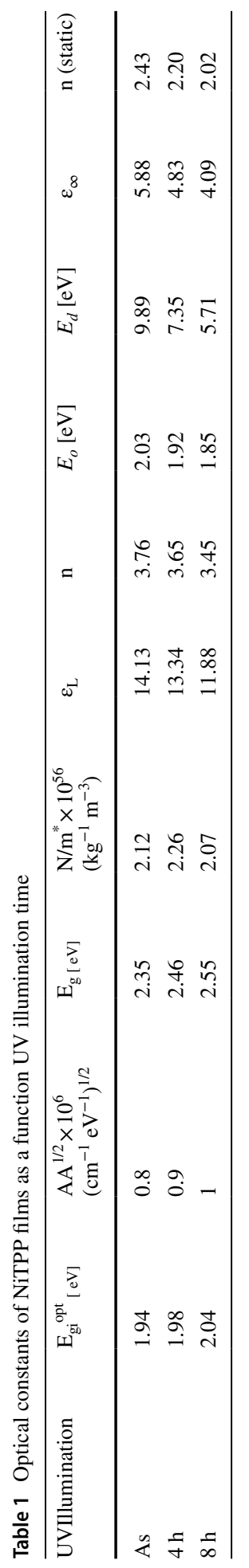


Fig. $5 \mathrm{n}$ and $\mathrm{k}$ of NiTPP films

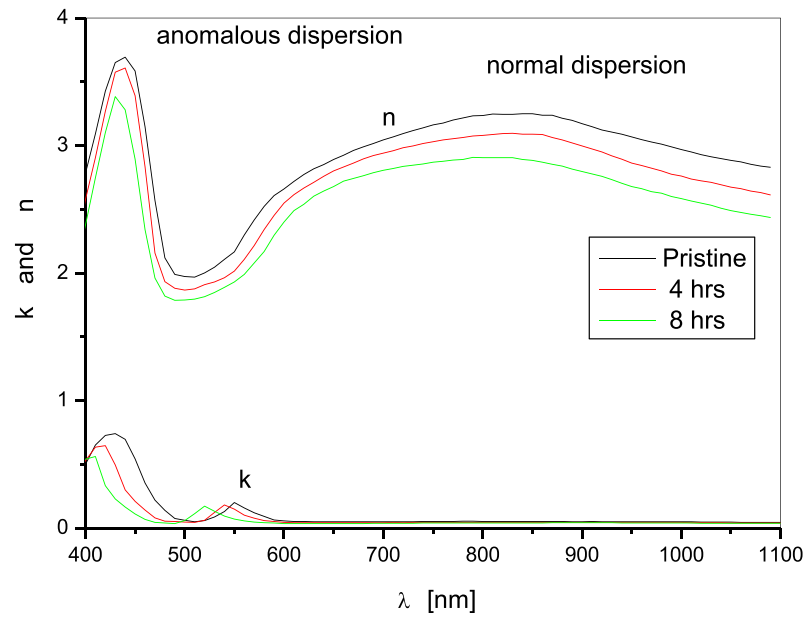

Fig. $6 n^{2} V s \lambda^{2}$ of NiTPP films

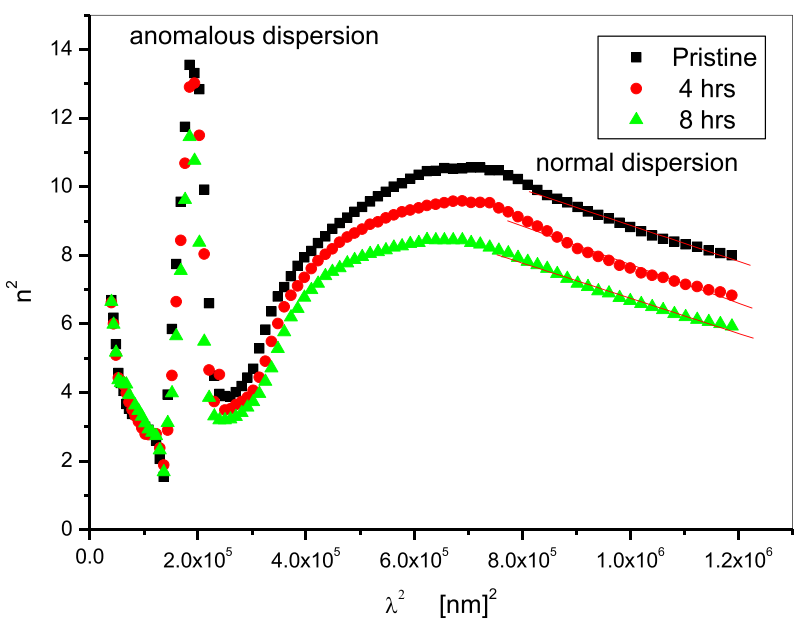

Fig. $7\left(n^{2}-1\right)^{-1} \mathrm{Vs}(h \nu)^{2}$ of NiTPP films

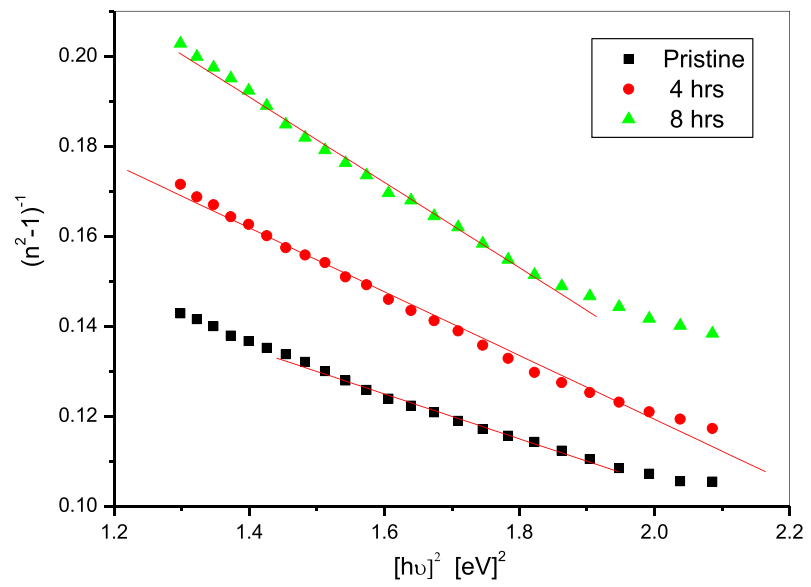


Fig. $8 \varepsilon_{1}, \varepsilon_{2}$ and $\tan (\delta) \mathrm{Vs}(\mathrm{h} \nu)$ of NiTPP films
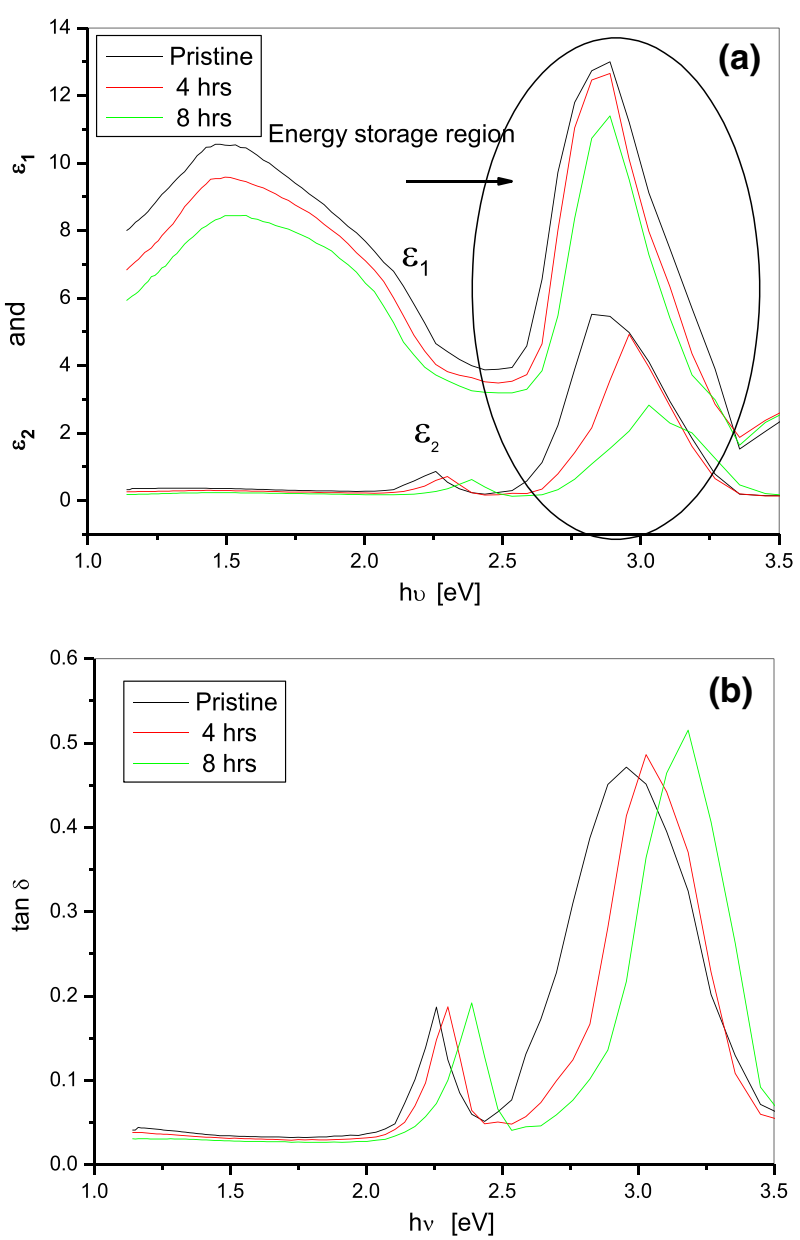

Recently, substances with high dielectric properties and low loss tangent (see Fig. 8a,b) have been shown to be good candidates for dielectric and energy storage applications (Zhang et al. 2016; El-Denglawey et al. 2020; Vidya and Thomas 2018). The loss tangent shows two maximums around energy values of $E_{g i}^{o p t}$ and $\mathrm{E}_{\mathrm{g}}$; the topmost value of $\tan (\delta)$ is 0.51 and corresponds to $8 \mathrm{~h}$ of UV illumination. The obtained value of $\tan (\delta)$ shows that the pristine and UV-illuminated NiTPP films are characterized by low energy loss (Zhang et al. 2016; Vidya and Thomas 2018). Accordingly, this result highlights the energy storage property of the NiTPP films as a function of UV illumination time, and the energy storage region can be elucidated in Fig. 8a,b. The value and the area of the two maximums of $\varepsilon_{1}$ and $\varepsilon_{2}$ decrease with an increasing UV illumination time, which demonstrates that the energy storage properties of the pristine and UV-illuminated NiTPP films can be tuned and tailored by the UV illumination time. 


\subsubsection{Optical conductivity}

The optical conductivity $\left(\sigma\left(\sigma_{1}\right.\right.$ and $\left.\left.\sigma_{2}\right)\right)$ represents the response of the material to electromagnetic wave photon absorption. Additionally, $\sigma$ provides some details about the structural and optoelectronic properties of the material (Marton et al. 1955; Ching et al. 1989).

As shown in Eq. 11, $\sigma$ and $\varepsilon$ are correlated; thus, $\sigma_{1}$ and $\sigma_{2}$ can be calculated as described before. Figure 9a,b shows both $\sigma_{1}$ and $\sigma_{2}$ vs. h $\nu$ as a function of UV illumination time.

After focusing on $\varepsilon_{1}, \varepsilon_{2}, \sigma_{1}$ and $\sigma_{2}$ in Figs. 8, 9a,b, $\sigma_{1}$ and $\varepsilon_{2}$ show a behavioral resemblance, and $\sigma_{2}$ and $\varepsilon_{1}$ are consistent with Eq. 11. (Fig. 10).

It is possible to discern that $\sigma_{1}$ and $\varepsilon_{2}$ display two peak edges, and these modest and prominent peak edges start at approximately $\mathrm{h} \nu=2 \mathrm{eV}$ and $2.5 \mathrm{eV}$, respectively. The modest peak edge is ascribed to indirect electronic transition within the band tails, which corresponds to $E_{g i}^{o p t}$, while the other edge is ascribed to the electronic transition between valence and conduction bands and corresponds to $\mathrm{E}_{\mathrm{g}}$.

In summary, at low energy, a high density of localized states (first peak) tends to shift to a lower density at high energy (second peak) based on the UV illumination time (Tauc

Fig. $9 \sigma_{1}$ and $\sigma_{2}$ Vs $(h \nu)$ of NiTPP films
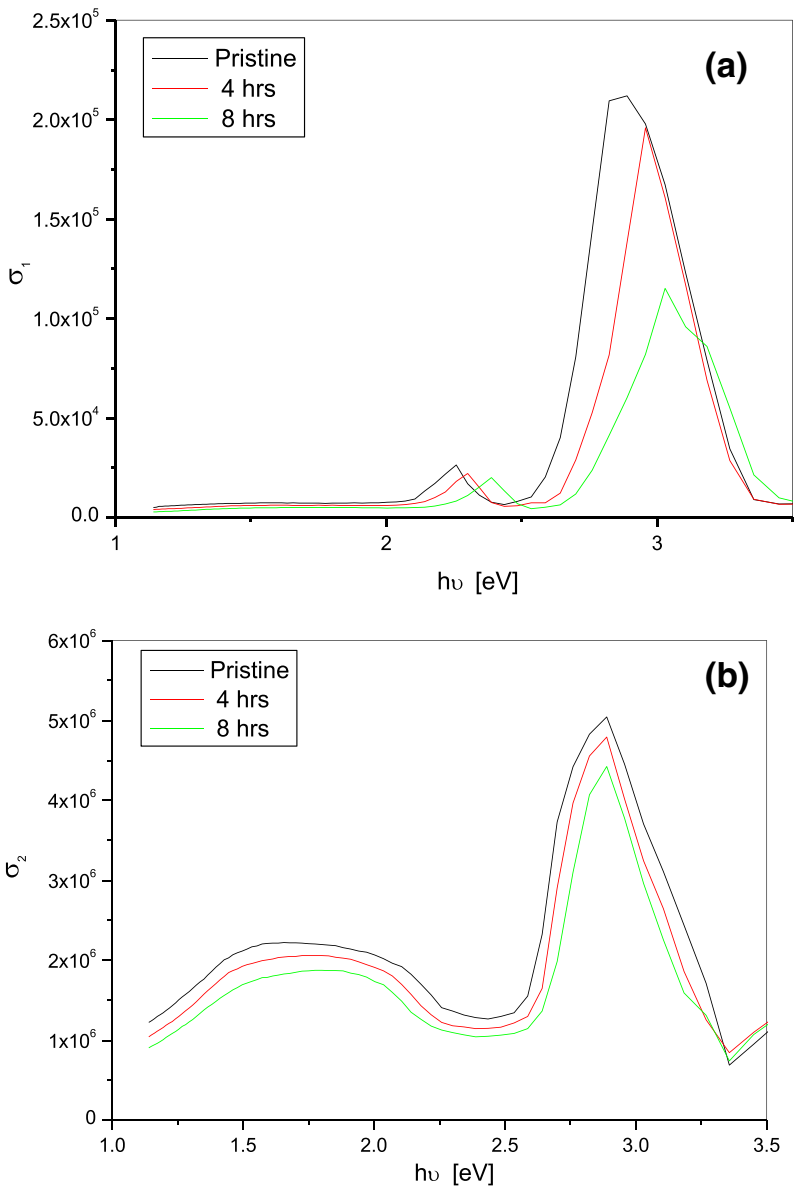


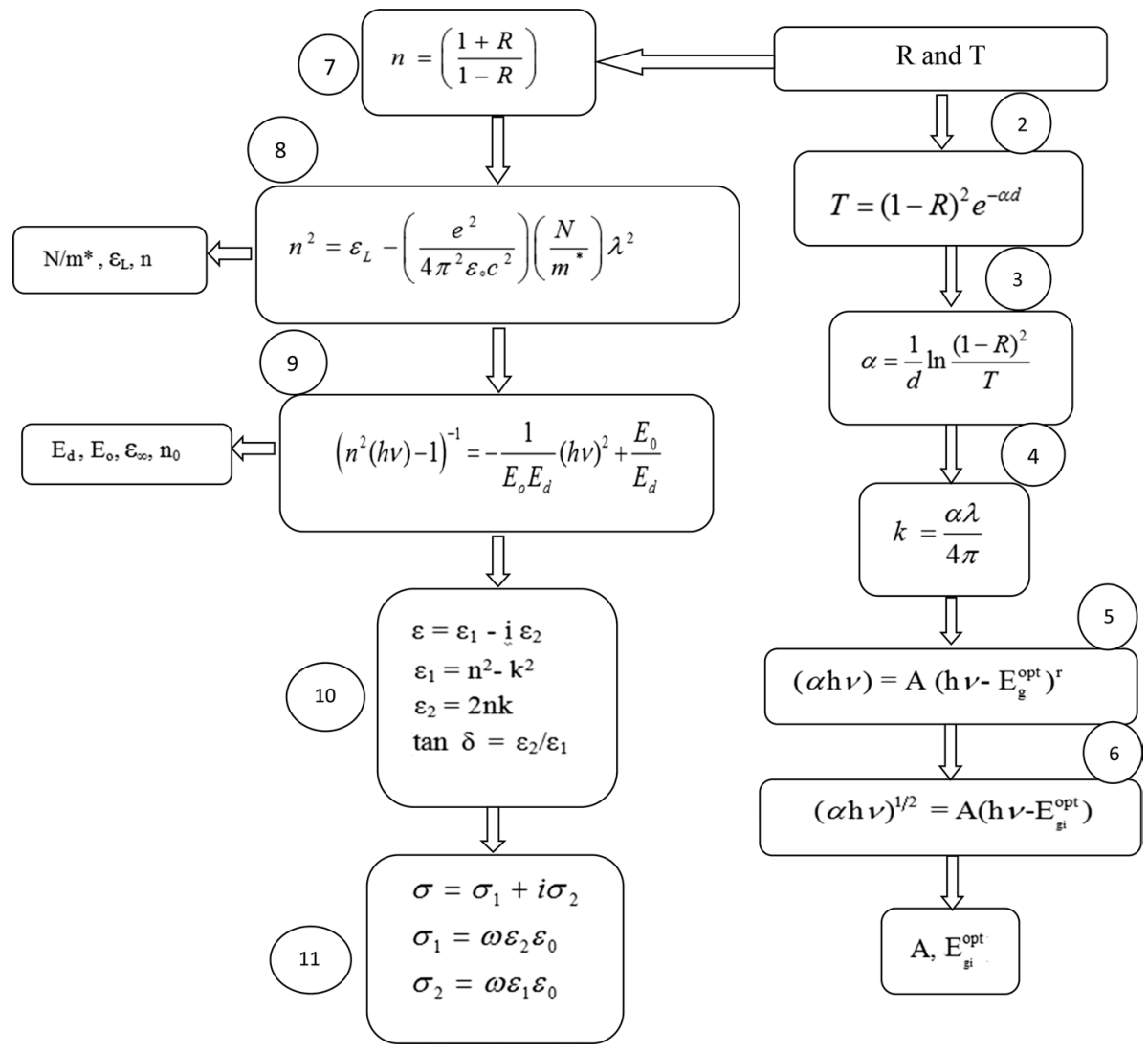

Fig. 10 Flow chart of the equations

1976; Mott and Davis 1971; El-Denglawey 2020). Consequently, during the transition stage from a high to a low density of localized states (order enhancement), the peak of optical conductivity increases from the modest to the prominent peak and shifts to higher energy. Accordingly, the UV illumination time causes a shift in the edges of the two peaks of $\sigma_{1}$ and $\varepsilon_{2}$ and $\sigma_{2}$ and $\varepsilon_{1}$ to a higher energy. Furthermore, $\sigma_{2}$ and $\varepsilon_{1}$ display a broad peak below $2 \mathrm{eV}$ due to the low attenuation of incident light and low absorption process (the topmost values of the skin depth), while $\sigma_{2}$ and $\varepsilon_{1}$ exhibit consistent $\sigma_{1}$ and $\varepsilon_{2}$ second peaks at a high energy. These results show that the features of $\varepsilon_{1}$ and $\varepsilon_{2}$ are due to $\sigma_{2}$ and $\sigma_{1}$ because $\varepsilon_{1}$ and $\varepsilon_{2}$ track $\mathrm{n}$ and $\mathrm{k}$, respectively (El-Denglawey 2020). This result indicates that both $\sigma_{1}$ and $\sigma_{2}$ can be tailored and engineered using the UV illumination time.

\section{Conclusions}

UV illumination times of 4 and $8 \mathrm{~h}$ were applied to pristine thermally evaporated NiTPP thin films. The pristine films were amorphous, and after 4 and $8 \mathrm{~h}$ of UV illumination, the NiTPP thin films turned to the crystalline phases with preferred orientations of (112), (103) and (004) at $2 \theta=15.19^{\circ}, 20.13^{\circ}$ and $25.43^{\circ}$, respectively; furthermore, crystallite 
sizes of $(13,18,16)$ and $(42,31,38) \mathrm{nm}$ are obtained after 4 and $8 \mathrm{~h}$ of UV illumination, respectively.

Transmission exhibits a blueshift, and its values increase while the reflectance values decrease. Due to the increase in structural order because of the 4 and $8 \mathrm{~h}$ of UV illumination, the $E_{g i}^{o p t}, \mathrm{E}_{\mathrm{g}}$ and constant $\mathrm{A}$ values increase. The optical constants are also seriously affected. Moreover, $N / \mathrm{m}^{*}$ shows increased values, while $\mathrm{n}, \mathrm{E}_{\mathrm{o}}, \mathrm{E}_{\mathrm{d}}, \varepsilon_{\mathrm{L}}$, and $\varepsilon_{\infty}$ show decreased values.

The prominent peaks observed for $\varepsilon_{1}$ and $\varepsilon_{2}$ correspond to the maximum conductivity $\left(\sigma_{2}\right.$ and $\left.\sigma_{1}\right)$, which provides an elegant confirmation that the NiTPP films would be good candidates for energy storage applications because they can be tuned and engineered by the UV illumination time.

Acknowledgements This study was funded by the Deanship of Scientific Research, Taif University, KSA [research project number 1-440-6142]. It is gratefully acknowledged.

\section{Declarations}

Conflict of interest Authors declare that there no conflict of interest.

\section{References}

Al-Asbahi, B.A., Qaid, S.M.H., Hezam, M., Bedja, I., A.S. : Effect of deposition method on the structural and optical properties of $\mathrm{CH} 3 \mathrm{NH} 3 \mathrm{PbI} 3$ perovskite thin films. Opt. M. 103, 109836 (2020)

Alburaih, H., El-Denglawey, A.: Aging effect on the structure and optical properties of nano $\mathrm{Cu}_{2} \mathrm{~S}$ films. Result Phys. 7, 1010-1015 (2017)

Alburaih, H.A., El-Denglawey, A.: Effect of deposition pressure on the optical and structural properties of nano GTC films. J. Ovonic Res. 15, 69-80 (2019)

Al-Harbi, F.F., El-Nahass, M.M., Soliman, H.S., El-Denglawey, A.: Nano structure and optical properties of two hours thermal aged AsAgS films deposited on quartz substrate: new time factor. Opt. Quant. Electron. 52, 1-9 (2020)

Al-Muntaser, A.A., El-Nahass, M.M., Oraby, A.H., Meikhail, M.S., Zeyada, H.M.: Structural and optical characterization of thermally evaporated nanocrystalline 5,10,15,20-tetraphenyl-21H,23H-porphine manganese (III) chloride thin films. Optik 167, 204-217 (2018)

Alptekin, O., Sen, B., Savk, A., Ercetin, U., Mustafov, S.D., Fellah, M.F., Sen, F.: Use of silica-based homogeneously distributed gold nickel nanohybrid as a stable nanocatalyst for the hydrogen production from the dimethylamine borane. Scientif. Rep. 10, 7215 (2020)

Anderson, H.L.: Building molecular wires from the colours of life: conjugated porphyrin oligomers. Chem. Commun. 23, 2323-2330 (1999)

Andirova, D.C.F., Cogswell, Y., Choi Lei, S.: Effect of the structural constituents of metal organic frameworks on carbon dioxide capture. Microporous Mesoporous Mater. 219, 276-305 (2016)

Barmak, K., Coffey, K.: Metallic films for electronic, optical and magnetic applications structure, processing and properties. Woodhead Publishing Limited, Oxford (2014)

Chen, Z., Gao, P., Wang, W., Klyatskaya, S., Karger, Z.Z., Wang, D., Kübel, C., Fuhr, O., Fichtner, M., Ruben, M.: A lithium-free energy storage device based on an alkyne-substituted-porphyrin complex. Chem. Sus. Chem. (2019). https://doi.org/10.1002/cssc.201901541

Ching, W.Y., Zhao, G.L., Zu, Y.N.: Intraband optical conductivity of $\mathrm{Bi}_{2} \mathrm{CaSr}_{2} \mathrm{Cu}_{2} \mathrm{O}_{8}$. Modern Physics Letter. 3, 263-269 (1989)

Chortos, A., Lim, J., To, J.W.F., Vosgueritchian, M., Dusseault, T.J., Kim, T.H., Hwang, S.W., Bao, Z.N.: Highly stretchable transistors using a microcracked organic semiconductor. Adv. Mater 26, 4253-4259 (2014)

Deepthi, K., Stamm, M., Gowd, E.B.: Factors influencing the formation of block copolymer-based supramolecular assemblies in bulk and thin films. Mater. Today Commun. 24, 101147 (2020)

Dongol, M., El-Denglawey, A., Abd El Sadek, M.S., Yahia, I.S.: Thermal annealing effect on the structural and the optical propertiesof Nano CdTe films. Optik 126, 1352-1357 (2015) 
Dongol, M., El-Denglawey, A., Elhady, A.F., Ebied, M.S.: Synthesis and the RDF fine structure of $\mathrm{Ge}_{0.15} \mathrm{Te}_{0.78} \mathrm{Cu}_{0.07}$ bulk alloy. Optik 127, 8186-8193 (2016)

Dongol, M., Abou Zied, M., Gamal, G.A., El-Denglawey, A.: The effects of composition and heat treatment on the structural and optical properties of $\mathrm{Ge}_{15} \mathrm{Te}_{85-\mathrm{x}} \mathrm{Cu}_{\mathrm{x}}$ thin films. Physica B. 353, 169-175 (2004)

Dongol, M., El-Denglawey, A., Elhady, A.F., Abuelwafa, A.A.: Structural properties of nano 5, 10, 15, 20-Tetraphenyl-21H,23H-porphine nickel (II) thin films. Curr. Appl. Phys. 12, 1334-1339 (2012)

El-Denglawey, A.: Structural, optical and electrical, properties of As-Se-Tl films: physical properties of AsSe-Tl films" edition:1. Lap Lampert Academic, Boston (2013)

El-Denglawey, A., Alburaih, H.A., Mostafa, M.M., Adam, M.S., Dongol, M., El-Nahass, M.M., Alotaibi, M.T., Makhlouf, M.M.: Dependence of nano new environmental organic semiconductor Nickel-(II)tetraphenyl-21H,23H- porphyrin films on substrate type for energy storage applications. Int. J. Environ. Sci. Technol. (2020). https://doi.org/10.1007/s13762-020-02829-3

El-Denglawey, A., Dongol, M., El-Nahass, M.M.: Photoinduced absorption edge shift of $\mathrm{As}_{20} \mathrm{Se}_{60} \mathrm{Tl}_{20}$ films. J. Lumin. 130, 801-804 (2010)

El-Denglawey, A., Makhlouf, M.M., Dongol, M., El-Nahass, M.M.: The effect of long term aging on the structural and optical properties of nano metallo- tetraphenylporphine films". J Mater. Sci: Mater. Electron. 26, 5603-5609 (2015)

El-Denglawey, A.: Illumination effect on the structural and optical properties of nano meso nickel (II) tetraphenyl-21H, 23H-porphyrin films induces new two hours photo bleached optical sensor. J. Lumin. 194, 381-386 (2018)

El-Denglawey, A., Makhlouf, M.M., Dongol, M.: The effect of thickness on the structural and optical properties of nano Ge-Te-Cu films. Results Phys. 10, 714-720 (2018)

El-Denglawey, A., Makhlouf, M.M., Dongol, M.: Physical aging effects on the structural and optical properties of nano As-Se-Tl films. J. Non-Cryst. Solids 449, 34-40 (2016)

El-Nahass, M.M., Ali, M.H., El-Denglawey, A.: Structural and optical properties of nano-spin coated solgel porous $\mathrm{TiO}_{2}$ films. Trans. Nonferr. Met. Soc. China. 22, 3003-3011 (2012)

El-Nahass, M.M., Soliman, H., El-Denglawey, S.A.: Absorption edge shift, optical conductivity, and energy loss function of nano thermal-evaporated $\mathrm{N}$-type anatase $\mathrm{TiO}_{2}$ films. Appl. Phys. A 122, 775-786 (2016)

Fella, M.J., Pagel, L., Chen, C., Goldberg, M.H., Herberz, M., Huebner, G.M., Sareeng, S., Hahnel, U.J.J.: Validity of energy social research during and after COVID-19: challenges, considerations, and responses. Energy Res. Soc. Sci. 68, 101646 (2020)

Figà, V., Chiappara, C., Ferrante, F., Casaletto, M.P., Principato, F., Cataldo, S., Chen, Z., Usta, H., Facchetti, A., Pignataro, B.: Symmetric naphthalene diimide quaterthiophenes for electropolymerized electrochromic thin films. J. Mat. Chem. C 3, 5985-5994 (2015)

Figà, V., Luc, J., Kulyk, B., Baitoul, M., Sahraoui, B.: Characterization and investigation of NLO properties of some selected electrodeposited polythiophenes. J. Eur. Opt. Soc. 4, 09016 (2009)

Gamboa, M., Campos, M., Torres, L.A.: Study of the stability of 5,10,15,20-tetraphenylporphine (TPP) and metalloporphyrins NiTPP, CoTPP, CuTPP, and ZnTPP by differential scanning calorimetry and thermogravimetry. J. Chem. Thermodyn. 42, 666-674 (2010)

Gao, P., Chen, Z., Karger, Z.Z., Mueller, J.E., Jung, C., Klyatskaya, S., Diemant, T., Fuhr, O., Jacob, T., Behm, R.J., Ruben, M., Fichtner, M.: Porphyrin complex as self-conditioned electrode material for high performance energy storage. Angew. Chem. Int. Ed. (2017). https://doi.org/10.1002/anie.20170 2805

Li, G., Xuan, Q., Pei, G., Su, Y., Ji, J.: Effect of non-uniform illumination and temperature distribution on concentrating solar cell - a review. Energy 144, 1119-1136 (2020)

Gilberdt, P.: The anomalous skin effect and the optical properties of metals. J. Phys. F: Met. Phys. 12, 18451860 (1982)

Hassan, M., Al-Ta'ii, J.: Investigating the optical characteristics of SSNTD-LR115 by using different UV radiation dose. Radiat. Measurements 132, 106262 (2020)

Idris, N., Yusibani, M., Yusibani, E.: The effect of the thickness of the glass plate of a hollow prism on the accuracy of measuring the refractive index of edible oil. Optik 217, 164834 (2020)

Jason, D., Xue, M.: Organic semiconductors and their applications in photovoltaic devices. J. Poly. Rev. 52, 1-37 (2012)

Kaltenbrunner, M., Kettlgruber, G., Siket, C., Schwodiauer, R., Bauer, S.: Arrays of ultracompliant electrochemical dry gel cells for stretchable electronics. Adv. Mater. 22, 2065-2067 (2010)

Kambezidis, H.D.: The Solar Resource. Comprehensive Renew. Energy (2012). https://doi.org/10.1016/ B978-0-08-087872-0.00302-4

Karger, Z.Z., Gao, P., Ebert, T., Klyatskaya, S., Chen, Z., Ruben, M., Fichtner, M.: New organic electrode materials for ultrafast electrochemical energy storage. Adv. Mater. 31, 1806599 (2019) 
Kulyk, B., Kapustianyk, V., Figà, V., Sahraoui, B.: Quadratic nonlinear optical parameters of 7\% MgOdoped LiNbO3 crystal. Opt. Mater. 56, 36-39 (2020)

Kuzemko, C., Bradshaw, M., Bridge, G., Goldthau, A., Jewell, J., Overland, I., Scholten, D., Graaf, T., Westphal, K.: Covid-19 and the politics of sustainable energy transitions. Energy Res. Soc. Sci. (2020). https://doi.org/10.1016/j.erss.2020.101685

Kumar, M., Rani, S., Singh, J.P., Chae, K.H., Kim, Y., Park, J., Lee, H.H.: Structural phase control and thermochromic modulation of VO2 thin films by post thermal annealing. Appl. Surf. Sci. 529, 147093 (2020)

Leo, K., Hummert, M.: Doping effects on charge transport in organic materials, in handbook of organic materials for optical and optoelectronic. Elsevier (2013)

Lukyanov, A., Andrienko, D.: Extracting nondispersive charge carrier mobilities of organic semiconductors from simulations of small systems. Phys. Rev. B 82, 193202-202010 (2010)

Makhlouf, M.M., El-Denglawey, A.: Structural, thermal, spectroscopic, and spectral dispersion studies of nanocrystalline methyl red thin films. Japan. J. Appl. Phys. 57, 042401 (2018)

Marton, L., Leder, L.B., Mendlowitz, H.: Characteristic energy losses of electrons in solids, in "advances in electronics and electron physics. Academic Press, New York (1955)

Mastropietro, P., Rodilla, P., Batlle, C.: Emergency measures to protect energy consumers during the Covid-19 pandemic: a global review and critical analysis. Energy Res. Social Sci. 68, 101678 (2020)

Moan, J.: Visible light and UV radiation. in: radiation at home, outdoors and in the workplace Paakkonen. Scandinavian Science Publisher, Oslo (2001)

Moss, T.S., Burrell, G.J., Ellis, E.: Semiconductor opto-electronics. Butterworths, London (1973)

Mott, N.F., Davis, E.A.: Electronic processes in non-crystalline materials. Oxford University Press, Oxford (1971)

Özdal, T., Chtouki, T., Kavak, H., Guichaoua, D., Erguig, H., Sahraoui Mysliwiec, B.: Effect of annealing temperature on morphology and optoelectronics properties of spin-coated CZTS thin films. J. Inorg. Organomet. Polym. (2020). https://doi.org/10.1007/s10904-020-01646-y

Pankove, J.I.: Optical properties in semiconductors. Dover publication, NY (1971)

Pfeiffer, M., Leo, K., Zhou, X., Huang, J.S., Hofmann, M., Werner, A., Nimoth, J.B.: Doped organic semiconductors: physics and application in light emitting diodes. Organ. Electron. 4, 89-103 (2003)

Qiang, W., Bin, Z.H., Yi, L.X., Ping, H.Q., Sheng, G.I.: Study of the skin depth and defect detection in carbon fiber composites with terahertz waves. Optik 178, 1035-1044 (2018)

Root, S.E., Savagatrup, S., Printz, A.D., Rodriquez, D., Lipomi, D.J.: Mechanical properties of organic semiconductors for stretchable, highly flexible, and mechanically. Robust Electron. Chem. Rev. 117, 6467-6499 (2017)

Saad, A.F., Ibraheim, M.H., Hamada, M.: IR radiation-induced changes in the optical and registration properties of a CR-39 nuclear track detector. Radiat. Meas. 126, 106129 (2019)

Saiter, J.M.: Physical ageing in chalcogenide glasses. Optoelectron Adv. Mater. 235, 685-694 (2001)

Savagatrup, S., Printz, A.D., O’Connor, T.F., Zaretski, A.V., Lipomi, D.J.: Molecularly stretchable electronics. Chem. Mater. 26, 3028-3041 (2014)

Sen, B., Kuzu, S., Demir, E., Yıldırır, E., Sen, F.: Highly efficient catalytic dehydrogenation of dimethyl ammonia borane via monodisperse palladium- nickel alloy nanoparticles assembled on PEDOT. Int. J. Hydrogen Energy (2017). https://doi.org/10.1016/j.ijhydene.2017.05.115

Smith, K.M.: Porphyrins and metalloporphyrins. Elsevier, Amsterdam (1975)

Smokal, V., Kharchenko, O., Krupka, O., Studzinsky, S., Davidenko, N., Figà, V.: Changes in optical properties of azopolymers in an electric field. Ukr. J. Phys. 65, 686-690 (2020)

Soliman, H.S., Saadeldin, M.M., Sawaby, K., Eldenglawey, A.: Properties of nano and micro p-type $\mathrm{Cu}_{2} \mathrm{~S}$ films. CJPAS 9, 3247-3257 (2015)

Souleh, K., Amor, A., Edjici, H.L., Agoun, B.L., Boucenna, M., Bouarissa, N.: Structural parameters and optical spectra of $\mathrm{Zn1-xCoxO}$ ternary alloys with zinc- blende, rocksalt and wurtzite phases. Optik 224, 165732 (2020)

Sugiyama, M., Fujii, K., Nakamura, S.: Solar to chemical energy conversion: theory and application. Springer international publishing, Switzerland (2016)

Tamilselvan, M., Vimalan, S., Potheher, I.V., Jeyasekaran, R., Yogam, F., Madhavan, J.: Generation of $532 \mathrm{~nm}$ laser radiation and phase matching properties of organic nonlinear optical material. Optik 125, 164-169 (2014)

Tauc, J.: Amorphous and liquid semiconductors. Plenum, New York (1976)

Tanaka, K.: Optical properties and photoinduced changes in amorphous As-S films. Thin Solid Films 66, 272-279 (1980)

Tang, C.W.: Two layer organic photovoltaic cell. Appl Phys Lett 48, 183-185 (1986) 
Trugler, A.: Optical properties of metallic nanoparticles: basic principles and simulation. Springer International Publishing, Switzerland (2016)

Vidya, S., Thomas, J.K.: Optical and dielectric investigations of nano crystalline scheelite $\mathrm{A}_{0.5} \mathrm{~B}_{0.5} \mathrm{Mo}_{\mathrm{O} 4}$ ( $\mathrm{A}=\mathrm{B}=\mathrm{Ba}, \mathrm{Sr}$ and $\mathrm{Ca})$. Bull. Pure Appl. Sci. 37, 26-34 (2018)

Wang, J.J., Chang, S.Y., Ouyang, F.Y.: Effect of substrate bias on the microstructure and properties of (AlCrSiNbZr)Nx high entropy nitride thin film. Surf. \& Coat. Technol. 393, 125796 (2020)

Warren, B.E.: X-ray diffraction reading. Addison-Wesley, New York (1969)

Wang, W., Pu, Y., Guo, X., Ouyang, T., Shi, Y., Yang, M., Li, J., Shi, R., Liu, G.: Enhanced energy storage properties of lead-free (Ca0. 5Sr0. 5) 1-1.5 xLaxTiO3 linear dielectric ceramics within a wide temperature range. Ceram. Int. 45, 14684-14690 (2019)

Wemple, S.H., DiDomenico, M.D.: Behavior of the electronic dielectric constant in covalent and ionic materials. Phys. Rev. B 3, 1338-1352 (1969)

Williamson, J.K., Hall, W.: X-ray line broadening from filed aluminum and wolfram. Acta Metall 1, 22-31 (1953)

Yang, W., Qu, P., Sun, J., Yue, Q., Su, H., Zhang, J., Liu, L.: Effect of alloying elements on stacking fault energies of $\gamma$ and $\gamma^{\prime}$ phases in Ni-based superalloy calculated by first principles. Vacuum 181, 109682 (2020)

Zhang, T.F., Tang, X.G., Liu, Q.X., Jiang, Y.P., Jiang, L.L., Luo, L.: Optical and dielectric properties of $\mathrm{PbZrO}_{3}$ thin films prepared by a sol-gel process for energy-storage application. Mater. Des. 90, 410415 (2016)

Publisher's Note Springer Nature remains neutral with regard to jurisdictional claims in published maps and institutional affiliations. 